\title{
BMJ Open Are there differences between those doctors who apply for a training post in Foundation Year 2 and those who take time out of the training pathway? A UK multicohort study
}

Jennifer Cleland, ${ }^{1}$ Gordon Prescott, ${ }^{2}$ Kim Walker, ${ }^{1,3}$ Peter Johnston, ${ }^{4,5}$ Ben Kumwenda (iD ${ }^{1}$

To cite: Cleland J, Prescott G, Walker $\mathrm{K}$, et al. Are there differences between those doctors who apply for a training post in Foundation Year 2 and those who take time out of the training pathway? A UK multicohort study. BMJ Open 2019;9:e032021. doi:10.1136/ bmjopen-2019-032021

\section{- Prepublication history for} this paper is available online. To view these files, please visit the journal online (http://dx.doi org/10.1136/bmjopen-2019032021).

Received 29 May 2019 Revised 16 October 2019 Accepted 04 November 2019

Check for updates

(C) Author(s) (or their employer(s)) 2019. Re-use permitted under CC BY-NC. No commercial re-use. See rights and permissions. Published by BMJ.

${ }^{1}$ Centre for Healthcare Education Research and Innovation (CHERI), University of Aberdeen College of Life Sciences and Medicine, Aberdeen, UK

${ }^{2}$ Lancashire Clinical Trials Unit, University of Aberdeen, Preston, UK

${ }^{3} \mathrm{NHS}$ Education for Scotland, Edinburgh, UK

${ }^{4}$ NHS Education for Scotland, North Deanery, Aberdeen, UK ${ }^{5}$ NHS Grampian, Aberdeen, UK

Correspondence to

Dr Jennifer Cleland;

jen.cleland@abdn.ac.uk

\section{ABSTRACT}

Introduction Knowledge about the career decisions of doctors in relation to specialty (residency) training is essential in terms of UK workforce planning. However, little is known about which doctors elect to progress directly from Foundation Year 2 (F2) into core/specialty/ general practice training and those who instead opt for an alternative next career step.

Objective To identify if there were any individual differences between these two groups of doctors. Design This was a longitudinal, cohort study of 'home' students who graduated from UK medical schools between 2010 and 2015 and completed the Foundation Programme (FP) between 2012 and 2017.

We used the UK Medical Education Database (UKMED) to access linked data from different sources, including medical school performance, specialty training applications and career preferences. Multivariable regression analyses were used to predict the odds of taking time out of training based on various sociodemographic factors.

Results 18 380/38 905 (47.2\%) of F2 doctors applied for, and accepted, a training post offer immediately after completing F2. The most common pattern for doctors taking time out of the training pathway after FP was to have a 1-year (7155: $38.8 \%$ ) or a 2-year break (2605: $14.0 \%)$ from training. The odds of not proceeding directly into core or specialty training were higher for those who were male, white, entered medical school as (high) school leavers and whose parents were educated to degree level. Doctors from areas of low participation in higher education were significantly $(0.001)$ more likely to proceed directly into core or specialty training.

Conclusion The results show that UK doctors from higher socioeconomic groups are less likely to choose to progress directly from the FP into specialty training. The data suggest that widening access and encouraging more socioeconomic diversity in our medical students may be helpful in terms of attracting F2s into core/specialty training posts.

\section{INTRODUCTION}

The aim of the medical education and training pathway is to provide enough appropriately

\section{Strengths and limitations of this study}

- This is the first study in a UK setting to look in detail at the association between individual characteristics, including socioeconomic background, and career-related behaviour (applying for a training post in Foundation Year 2 or not).

- This is a UK-wide, multicohort study of the career decisions of 'home' doctors who successfully completed first stage of generic postgraduate training and were eligible to apply for a specialty post.

- The study used the Educational Performance Measure of the UK Foundation Programme (FP) selection score measured 2 years before applications for specialty training as an indicator of academic performance.

- This is a quantitative study, so it tells us about aggregate patterns of behaviour, but it does not tell us the reasons for these patterns. To understand more about why doctors are taking time out of training post-FP requires in-depth exploratory work.

trained and competent doctors (supply) to meet the current and anticipated healthcare needs of the population (demand). ${ }^{1-3}$ The accurate prediction of medical workforce supply depends on doctors progressing upwards through the stages of medical education and training in ways predicted by the system. ${ }^{4}$ However, in the UK, for example, large numbers of early career doctors are not applying for a specialty training post (residency) at the time when they first become eligible to do so in the second year of the Foundation Year 2 (F2). Instead, the increasing norm is to take a break from the training pathway: more than $50 \%$ of doctors at the end of the Foundation Programme (FP) do not proceed directly to core/specialty training. ${ }^{56}$ In other words, more than one in two of UK medical graduates in recent years 
take time out of the training pathway at the first natural opportunity, at the point when they have full registration and are eligible to apply for specialty training.

There are several common sorts of alternative positions for doctors who do not proceed directly from foundation to core or specialty training. The majority continue to work in the UK, either in National Health Service (NHS) posts that are not part of a training programme (shortterm or locum 'service jobs') or, increasingly, in academic or development fellowship posts. The latter are proliferating in number across the country and can provide mutually beneficial breadth to clinical experience, keeping early career doctors in the UK delivering clinical service especially to support rota gaps but also supporting medical education and other areas of activity. ${ }^{7}$ The last pathway is working overseas, ${ }^{8}$ usually (but not always) for a short time before returning to the UK workforce. ${ }^{9}$

Recent research indicates that these alternative career behaviour patterns seem at least in part a reaction to lacking work-life balance during the $\mathrm{FP}^{10}$ and wanting more time to consider future career plans before entering what is perceived as the rigours of specialty training. ${ }^{811}$ However, the increasing number of early career doctors not proceeding directly into core or specialty training is a major issue for the UK healthcare system where such trainees are integral to service delivery at more senior level. The system has not adjusted to insufficient F2 doctors applying for training posts, resulting in short-staffed services and compromised healthcare delivery. ${ }^{6} 1213$ Moreover, unfilled training posts mean a shortage in the flow of doctors trained to specialist registration (ie, consultant or general practitioner (GP)) to replace doctors who are retiring. ${ }^{14} 15$

The system needs to be more cognisant that many new graduates are delaying their entry into specialty training and may need adjusting accordingly to take advantage of this shift in behaviour. It is critical to know more about who is taking time out of training and who is not in order to inform change. Much is known about the generic factors that influence medical careers decision making (eg, gender, ethnicity, job satisfaction, ${ }^{16}$ wish for work-life balance, financial remuneration, exposure to a particular specialty).${ }^{17-22}$ However, no study to date has examined the differences and similarities between those doctors who progress directly from foundation to core or specialty training seamlessly and those who pursue a different next career step. Knowing more about the differences between these groups can inform policy and practice in relation to medical selection, training design, attracting trainees to the breadth of specialties required for the workforce, and thus ensure sufficient doctors to deliver service now and in the future. ${ }^{1223-25}$

Our aim, therefore, was to explore differences between two groups: doctors who graduated from UK medical schools ('home' students) who proceed directly into core/ specialty including general practice (GP) training after F2 and those who take an alternative career step (which equates to time out of the training pathway/delaying time to the next stage of the formal training pathway). We were interested specifically in whether there were any differences between groups in terms of individual characteristics, educational performance at medical school and foundation school, and their specialty training preferences in terms of applying for specialty training or not in F2.

\section{METHODS}

\section{Study context}

UK medical students spend between 4 and 6 years at medical school before they enter the generic 2-year training programme (the FP), which bridges the gap between finishing medical school and becoming eligible to apply for specialty (residency) training. At the end of the first year of the FP, doctors who have successfully achieved their competencies gain full registration with the General Medical Council (GMC). Following this, the second year of the FP (F2) is the first opportunity for doctors to apply for a specialty (residency) training post.

\section{Data description}

This was a longitudinal multicohort study, following students who graduated from UK medical schools between 2010 and 2015 ('home' students) and completed the FP between 2012 and 2017, to examine their career-related behaviour (proceeding directly into core or specialty training or taking a break from the training pathway).

We used linked individual-level data from the UK Medical Education Database (UKMED: https://www. ukmed.ac.uk/) as the basis for this study. UKMED allows the analysis of data from a number of sources, including medical school admissions and assessment, postgraduate selection, assessment and training outcomes, and trainee surveys. ${ }^{26}$

UKMED contains self-declared demographic data such as age, gender and ethnicity. Following Kumwenda et $a l,{ }^{27}$ in this study we grouped ethnicity as either white (the majority ethnic group) or non-white. UKMED also contains variables that relate to socioeconomic status. These are of particular interest in terms of examining factors that may be associated with performance in students from different backgrounds, particularly in terms of widening participation. ${ }^{27-33}$ They include whether or not the family received income support; entitlement to free school meals; POLAR, which is an indicator of the participation of young people in higher education by geographic area; type of school (state funded or privately funded) and parental education.

We included the variable of school leaver or mature at the time of entry to medical school. In the UK, most students enter medicine as school leavers aged 17-20 years. However, there has been a focus on attracting graduates into medicine over the last 20 years or so as a means to diversify the medical student population. ${ }^{34}$ Graduates now make up nearly a quarter of the contemporary UK medical student population. ${ }^{27}$ Defining graduate status 
is complex, so we categorised age into 'school leaver' or 'mature' at the time of entry.

The type of high school attended was defined according to funding criteria, whether state funded or privately funded. Here in the UK, state-funded education is free and mostly non-selective, while privately funded schools are selective, they require pupils to pay tuition fees and have a greater proportion of pupils from affluent backgrounds. While the link between funding and selection is not universal, this categorisation is a commonly used contextual factor in medical admissions and has been used as a variable in previous studies. ${ }^{29}$

We also included country of medical qualification (UK country: England, Scotland, Wales and Northern Ireland) and place of foundation training in the analysis. At the time of writing this paper, there were 21 foundation schools in the UK. Northern Ireland, Scotland and Wales have one foundation school each, and the rest of the foundation schools are in England. We also included type of medical programme -5 years, 4 years (graduate entry) or 6 years (extended programmes).

Finally, we included a measurement of performance at medical school. All medical students studying in the UK who wish to enter the FP obtain two indicators of performance: an Educational Performance Measure (EPM) and a score on a bespoke situational judgement test. ${ }^{35-38}$ Our interest in this paper was the performance on medical school assessments, so we looked only at EPM. The EPM is a decile ranking (within each school) of an individual student's academic performance at medical school except the final year plus an additional seven points for additional educational achievements (eg, a (non-medical) degree, publications). Students in the lowest decile for educational assessments within each medical school receive a rank of 34 and those in the highest decile 43 . Therefore, the combined EPM score has a maximum of 50 points.

\section{Outcome measures}

UKMED also includes career choice data from ORIEL, a centralised online system for managing specialty recruitment and career progression in medical training (https://www.oriel.nhs.uk). As stated earlier, doctors who have full GMC registration and who are expected to have successfully completed the FP, or have already done so, are eligible to apply for a specialty post anywhere in the UK via a competitive national selection process. Specialty posts are offered on the basis of ranking, and individuals can only accept one post at any given time.

We identified 56 medical training pathways in ORIEL. These pathways are the route to specialist registration for doctors as defined by the Royal College curricula approved by the GMC. ${ }^{39}$ For the purposes of analysis, we grouped these 56 pathways into 13 categories, following advice from NHS Education Scotland (personal communication, December 2017). These were: Anaesthesia; ACCS (Intensive Care, Anaesthetics, Emergency Medicine); Emergency Medicine; Diagnostics; General
Practice; Medical Specialties; Surgical Specialties; Mental Health/Psychiatry; Obstetrics and Gynaecology; Public Health; Pathology; Radiology; Medical Paediatrics and Ophthalmology. Note that ACCS is a 3-year core training programme that rotates through emergency medicine, general (internal) medicine, anaesthetics and intensive care medicine. Although ACCS incorporates emergency medicine and anaesthesia, it is a different training pathway from the single-specialty core training pathways, hence being included separately.

The GMC's National Training Survey data is also held within UKMED. This provided granular information in terms of stated career preference (eg, fellowship posts, specialty training in the future), in response to the question: On completion of the FP, which specialty for further training (or other option) do you currently expect to be your first choice? This data was collected from all doctors at the time of commencing the FP.

\section{Statistical analysis}

All the data analyses were done using IBM SPSS Statistics for Windows, V.24 (IBM Corp, Armonk, New York, USA). The study population was assigned into two categories, those who applied and accepted a specialty post after finishing F2 (when they were first eligible to do so) and those who did not immediately apply. This latter group was categorised as not proceeding directly into training (instead choosing another career option before continuing along the training pathway to pursue alternative career options). Categorisation was primarily based on the year they finished F2 and the year they accepted a specialty offer. Therefore, we looked at the point in time when the offer was accepted, and we considered all 'accepted offers' after 1 year or more as not proceeding directly into specialty training. Where a doctor had applied for a training post but had not received an offer in the study follow-up period (see table 1 and later), they were removed from the analysis.

We used $\chi^{2}$ tests to examine the bivariate relationships between doctors' sociodemographic characteristics and the outcome measure, not proceeding directly into training/proceeding directly to core or specialty training. We used the Mann-Whitney test to compare the measure of the central tendency of the performance at medical school (EPM) between the two categories. Statistical significance was set a priori at $p<0.05$. We employed multivariable binary logistic regression analysis to predict the odds of taking time out of the training pathway based on the factors that were statistically significant in the test of association. The specific factors for which we adjusted for were those found to be statistically significant at the $5 \%$ significance level in the univariate analyses. The multivariable model for the odds of taking time out of training was refined to exclude variables that were no longer significant when considered in combination. We also presented descriptive statistics for the response to the question on first choice specialty above, split by whether or not doctors proceeded directly into training. 


\begin{tabular}{|c|c|c|}
\hline & $\mathbf{n}$ & $\%$ of total \\
\hline $\begin{array}{l}\text { Proceeding directly into a core } \\
\text { or specialty training post after } \\
\text { F2 }\end{array}$ & 18380 & 47.3 \\
\hline $\begin{array}{l}\text { Taking time out of training/ } \\
\text { pursing an alternative career } \\
\text { step }\end{array}$ & 18445 & 47.4 \\
\hline
\end{tabular}

step

\begin{tabular}{|c|c|c|}
\hline $\begin{array}{l}\text { Applying for a post but not } \\
\text { offered one in the study follow- } \\
\text { up period }\end{array}$ & 2075 & 5.3 \\
\hline Total & 38905 & \\
\hline $\begin{array}{l}\text { Time taken out of training/not } \\
\text { proceeding directly into a core } \\
\text { or specialty training post after } \\
\text { F2 }\end{array}$ & $\mathrm{n}$ & $\begin{array}{l}\% \text { of those } \\
\text { taking time out } \\
\text { of training }\end{array}$ \\
\hline $\begin{array}{l}\text { Returned into training after } 1 \text { - } \\
\text { year break }\end{array}$ & 7155 & 38.8 \\
\hline $\begin{array}{l}\text { Returned into training after } 2- \\
\text { year break }\end{array}$ & 2605 & 14.1 \\
\hline $\begin{array}{l}\text { Returned into training after } 3 \text { - } \\
\text { year break }\end{array}$ & 795 & 4.3 \\
\hline $\begin{array}{l}\text { Returned into training after } 4 \text { - } \\
\text { year break }\end{array}$ & 235 & 1.7 \\
\hline $\begin{array}{l}\text { Applied, offered, but did not } \\
\text { accept the offer in the period } \\
\text { of follow-up }\end{array}$ & 2005 & 10.9 \\
\hline $\begin{array}{l}\text { Finished F2 and still not } \\
\text { applied for a training post in } \\
\text { the period of follow-up }\end{array}$ & $5650^{*}$ & $30.6^{\star}$ \\
\hline Total & 18445 & \\
\hline
\end{tabular}

As per UKMED statistical disclosure controls, $\mathrm{n}$ are rounded to the nearest 5. https://www.ukmed.ac.uk/documents/UKMED_ research_process.pdf.

${ }^{*}$ The majority of these may have applied after the data cut-off point of 2017.

\section{Patient and public involvement}

Patients and the general public were not involved in the design of this research.

\section{Ethics and data access}

Access to the data was limited to specific members of the research team via a safe haven (to ensure adherence to the highest standards of security, governance and confidentiality when storing, handling and analysing identifiable data). Ethics approval was not required because the focus of this study was a secondary analysis of anonymised data and because of the strict research agreements and access arrangements put into place by the GMC, the data controller for UKMED. The Medical Schools Council (MSC) agreed that all approved applications for research projects using data exclusively held by UKMED would meet the criteria for a blanket exemption from the need to apply for ethics approval. ${ }^{26}$
RESULTS

Our sample was the cohorts who graduated from UK medical schools between 2010 and 2015 and who completed the FP between 2012 and 2017. Our specific focus was those individuals who were domiciled in the UK before attending a UK medical school, so-called home students, as UKMED holds sociodemographic data for this group ( $n=38$ 905: note numbers are rounded to the nearest five as per UKMED statistical disclosure controls).

Table 1 illustrates the patterns of career-related behaviour for our sample (applying for a specialty training post or taking time out of the training pathway). In brief, table 1 shows that just under half (47.3\%) of F2 doctors applied for, and accepted, a training post offer immediately after completing the foundation training, whereas $47.4 \%$ took time out of the training pathway. The remaining 5.3\% applied for a training post at least once, but never received an offer in the study follow-up period.

Table 1 also shows that the most common pattern in those 18445 doctors taking time out of the training pathway/pursuing an alternative career step was to have a 1-year (38.8\% of those taking time out) or a 2-year break (14.0\% of those taking time out) after completing the FP. Note that these figures are an amalgamation of data from several cohorts and so the figures are different from those of any one of the year groups of FP doctors in the sample.

Within the 18445 who did not immediately apply and take up an offer of a training post, 2005 (5.2\% of the total number of students and $10.9 \%$ of those taking time out of the training pathway) applied for but did not accept an offer.

We then removed those who had applied for a training post but were not offered one $(n=2075$, see table 1$)$, as we did not have outcome data (specialty choice) for this group. Thus, our analysis from this point on focuses on data from 36825 doctors.

Table 2 presents a detailed breakdown of the sample, comparing the sociodemographic characteristics of doctors who applied for core or specialty training in F2 and those who did not instead taking time out of the training pathway. Note that the valid numbers and percentages vary due to varying degrees of missing data. We assumed that data was missing not at random so did not remove observations with missing values nor did we impute data.

Table 2 shows significant differences between groups in terms of applying for a training post in F2 or taking time out of the training pathway. All differences were statistically significant at $\mathrm{p}<0.001$. The following doctors were significantly more likely not to choose not to proceed directly into core or specialty training after the FP: males compared with females $(52.6 \%$ vs $48.3 \%$, respectively); those who entered medical school as school leavers compared with their mature entry counterparts (52.9\% vs $40.6 \%)$; those whose parents were educated to a degree level compared with those who were first in family to university ( $47.2 \%$ vs $41.9 \%)$. Doctors from areas of low participation in higher education were less likely 
Table 2 Relationship between sociodemographic factors, proceeding directly into a training post or taking time out of the training pathway after Foundation Year 2

\begin{tabular}{|c|c|c|c|c|c|}
\hline & \multicolumn{2}{|c|}{$\begin{array}{l}\text { Proceeded directly into core or } \\
\text { specialty training }\end{array}$} & \multicolumn{2}{|c|}{ Took a break from training } & \multirow[b]{2}{*}{$P$ value } \\
\hline & $\mathbf{n}$ & Row \% & $\mathbf{n}$ & Row \% & \\
\hline \multicolumn{6}{|l|}{ Gender } \\
\hline Male & 7310 & 47.4 & 8100 & 52.6 & \multirow[t]{2}{*}{$<0.001$} \\
\hline Female & 11070 & 51.7 & 10350 & 48.3 & \\
\hline \multicolumn{6}{|l|}{ Age on entry to medical school } \\
\hline Mature & 5000 & 59.4 & 3415 & 40.6 & $<0.001$ \\
\hline \multicolumn{6}{|l|}{ Ethnicity } \\
\hline Asian or Asian British & 4220 & 58.2 & 3040 & 41.8 & \multirow[t]{3}{*}{$<0.001$} \\
\hline Black or Black British & 430 & 47.5 & 485 & 52.5 & \\
\hline Not stated & 55 & 51.4 & 50 & 48.6 & \\
\hline \multicolumn{6}{|l|}{ Income support } \\
\hline No & 11525 & 54.5 & 9600 & 45.5 & \multirow[t]{2}{*}{0.118} \\
\hline Yes & 1955 & 53.2 & 1720 & 46.8 & \\
\hline \multicolumn{6}{|l|}{ Free school meals } \\
\hline No & 12840 & 54.2 & 10840 & 45.8 & \multirow[t]{3}{*}{0.058} \\
\hline Yes & 1285 & 56.3 & 995 & 43.7 & \\
\hline Total & 14120 & 54.4 & 11835 & 45.6 & \\
\hline Low participation neighbourhood & 935 & 56.2 & 730 & 43.8 & \multirow[t]{2}{*}{$<0.001$} \\
\hline Other neighbourhood & 17360 & 49.6 & 17625 & 50.4 & \\
\hline \multicolumn{6}{|l|}{ UK country of origin (family home) } \\
\hline England & 15330 & 51.3 & 14530 & 48.7 & \multirow[t]{4}{*}{$<0.001$} \\
\hline Northern Ireland & 770 & 37.5 & 1280 & 62.5 & \\
\hline Scotland & 1460 & 45.5 & 1760 & 54.5 & \\
\hline Wales & 815 & 48.1 & 880 & 51.9 & \\
\hline \multicolumn{6}{|l|}{ Medical programme type } \\
\hline Standard Entry Medicine (5 years) & 15235 & 48.7 & 16070 & 51.3 & \multirow[t]{3}{*}{$<0.001$} \\
\hline Graduate Entry Programme (4 years) & 2265 & 59.1 & 1565 & 40.9 & \\
\hline $\begin{array}{l}\text { 6-Year Degree Programmes } \\
\text { (Including Medicine with Gateway/ } \\
\text { Foundation Programmes and } \\
\text { mandatory intercalating) }\end{array}$ & 635 & 49.5 & 645 & 50.5 & \\
\hline \multicolumn{6}{|l|}{ (High) School Type } \\
\hline State-funded high school or college & 13050 & 51 & 12565 & 49.0 & \multirow[t]{2}{*}{$<0.001$} \\
\hline $\begin{array}{l}\text { Privately funded/independent/fee } \\
\text { paying }\end{array}$ & 4805 & 47.6 & 5290 & 52.4 & \\
\hline
\end{tabular}


Table 2 Continued

\begin{tabular}{|c|c|c|c|c|c|}
\hline & \multicolumn{2}{|c|}{$\begin{array}{l}\text { Proceeded directly into core or } \\
\text { specialty training }\end{array}$} & \multicolumn{2}{|c|}{ Took a break from training } & \multirow[b]{2}{*}{$P$ value } \\
\hline & $\mathbf{n}$ & Row \% & $\mathbf{n}$ & Row \% & \\
\hline England & 16090 & 51.4 & 15195 & 48.6 & \multirow[t]{2}{*}{$<0.001$} \\
\hline Northern Ireland & 490 & 38.8 & 775 & 61.2 & \\
\hline \multicolumn{6}{|c|}{ Medical school performance } \\
\hline EPM (median (IQR)) & \multicolumn{2}{|c|}{$39.0(36.0-41.0)$} & \multicolumn{2}{|c|}{$39.0(36.0-41.0)$} & $<0.0001^{*}$ \\
\hline Mean & \multicolumn{2}{|c|}{38.88} & \multicolumn{2}{|c|}{38.67} & \\
\hline Skewness & \multicolumn{2}{|c|}{-0.14} & \multicolumn{2}{|c|}{-0.05} & \\
\hline Mean rank & \multicolumn{2}{|c|}{9411.99} & \multicolumn{2}{|c|}{9000.89} & \\
\hline Total & \multicolumn{2}{|c|}{$8270(45.3 \%)$} & \multicolumn{2}{|c|}{$10100(54.7 \%)$} & \\
\hline
\end{tabular}

As per UKMED statistical disclosure controls, $\mathrm{n}$ are rounded to the nearest 5. https://www.ukmed.ac.uk/documents/UKMED_research_ process.pdf

*The IQR between the two groups appears identical. However, the Mann-Whitney test that tests whether the two groups have the same location indicates that the mean rank between the two groups is statistically significant.

to take time out of the training pathway post-F2 than those from areas of high participation in higher education $(43.8 \%$ vs $50.4 \%)$, as were doctors who attended a graduate entry programme (40.9\% compared with $51.3 \%$ of their counterparts who attended a standard 5-year degree programme). Doctors who attended privately funded (high) school were more likely $(52.4 \%)$ to take time out of the training pathway than those who attended state-funded (high) school $(49.0 \%)$. When compared with other ethnic groups, trainees of Asian background $(41.8 \%)$ are less likely to take time out of the training pathway.

There were also some significant differences in terms of origin and place of foundation training. Trainees whose family home before entering medical school was in Northern Ireland $(62.5 \%)$ are significantly more likely to take time out/pursue alternative career routes after F2 than those from England (48.7\%), Scotland (54.5\%) and Wales $(51.9 \%)$. More trainees who completed their foundation training in Northern Ireland $(61.2 \%)$ and Scotland $(60.8 \%)$ took a break from the training pathway than those who completed their training at a foundation school in England (48.6\%) and Wales (52.5\%).

We did not find any statistically significant difference between income support and entitlement to free school meals and taking time out of the training pathway or progressing directly into specialty training after F2. Finally, although there appears a statistically significant association between educational performance at medical school (EPM) and taking time out of the training pathway, this result needs to be interpreted with caution. The Mann-Whitney test is most useful for the analysis of ordinal data for smaller datasets but is problematic for large datasets. A visual inspection of the histogram and box and whisker plots of the EPM variable confirms that the two groups were almost identical in terms of direction and magnitude of the skewness (see also table 2).

Eighteen thousand seven hundred and fifteen trainees in this cohort had information available on career preference. Table 3 shows a summary of stated career preference and whether or not a doctor took an alternative career step; $55 \%$ of those where the preference is recorded took time out of the training pathway compared with around half of all trainees in this cohort. The proportion of trainees who did not apply for a training post in F2 was observed to be higher in those whose career preference was in Academic Clinical Fellowship (66.3\%) and ACCS (Intensive Care) (69.0\%) compared with other specialties. The proportion of trainees who took time out of the training pathway was lower in those whose preference was in General Practice $(28.6 \%)$ and pathology specialties $(35.7 \%)$. Sixty-nine per cent of trainees who were undecided about their career preference pursued an alternative career step/ took time out of training immediately after F2. The $\chi^{2}$ test showed statistically significant association $(p<0.05)$ between career preference and whether or not a doctor took a break from formal training. 
Table 3 On completion of the Foundation Programme, which specialty for further training (or other option) do you currently expect to be your first choice?

\begin{tabular}{|c|c|c|c|c|c|}
\hline \multirow[b]{2}{*}{ Specialty preference } & \multirow[b]{2}{*}{ Specialty total } & \multicolumn{2}{|c|}{$\begin{array}{l}\text { Did not take a break from } \\
\text { formal training }\end{array}$} & \multicolumn{2}{|c|}{$\begin{array}{l}\text { Took a break from the formal } \\
\text { training pathway }\end{array}$} \\
\hline & & $n$ & Row \% & $\mathbf{n}$ & Row \% \\
\hline Academic Clinical Fellowship & 255 & 85 & 33.7 & 170 & 66.3 \\
\hline ACCS-Intensive Care Medicine & 225 & 70 & 31.0 & 155 & 69.0 \\
\hline Anaesthetics (core or ACCS) & 1555 & 660 & 42.4 & 895 & 57.6 \\
\hline Core medical training & 2825 & 1540 & 54.5 & 1285 & 45.5 \\
\hline $\begin{array}{l}\text { Emergency Medicine (including } \\
\text { ACCS-Emergency Medicine) }\end{array}$ & 690 & 265 & 38.3 & 425 & 61.7 \\
\hline General Practice & 3475 & 2480 & 71.4 & 995 & 28.6 \\
\hline $\begin{array}{l}\text { I intend to leave or take a break from } \\
\text { training }\end{array}$ & 2720 & 265 & 9.7 & 2455 & 90.3 \\
\hline Obstetrics and gynaecology & 585 & 260 & 44.3 & 325 & 55.7 \\
\hline Ophthalmology & 240 & 105 & 43.1 & 135 & 56.9 \\
\hline Paediatrics & 1015 & 480 & 47.6 & 530 & 52.4 \\
\hline Pathology specialties & 85 & 55 & 64.3 & 30 & 35.7 \\
\hline Psychiatry & 610 & 355 & 58.0 & 255 & 42.0 \\
\hline Public Health & 70 & 30 & 40.8 & 40 & 59.2 \\
\hline Radiology & 300 & 185 & 62.1 & 115 & 37.9 \\
\hline $\begin{array}{l}\text { Surgical training (CST or surgical } \\
\text { specialty started at ST1) }\end{array}$ & 1605 & 825 & 51.6 & 775 & 48.4 \\
\hline $\begin{array}{l}\text { Undecided (still considering between } \\
\text { specialties) }\end{array}$ & 2465 & 775 & 31.5 & 1690 & 68.5 \\
\hline Total & 18715 & 8430 & 45.1 & 10280 & 54.9 \\
\hline
\end{tabular}

As per UKMED statistical disclosure controls, n are rounded to the nearest 5. https://www.ukmed.ac.uk/documents/UKMED_research_ process.pdf

CST, core surgical training.

\section{Multivariate analysis}

We employed a binary logistic regression to predict the odds of taking time out of training based on the sociodemographic factors that were statistically significant in table 2. Note that although the EPM appeared to be statistically significant, we did not include it in the logistic regression model because the differences were extremely small.

In the model, we adjusted for the effect of gender, age category, ethnicity, parental education, country of domicile, programme type and foundation school.

The odds of taking time out of the training pathway were lower if the trainee was female, mature and nonwhite (table 4). The odds of taking time out of training were higher for trainees who came from families where at least one parent was educated to a degree level, attended a standard 5-year degree programme and completed their foundation training in Scotland or Wales. For example, the odds of taking a break from the formal training pathway were multiplied by a factor of 1.34 (increased by $34 \%$ ) for trainees originating from Northern Ireland compared with trainees from England (CI 1.14 to 1.58). Those who did their FP in Scotland or Wales had higher odds of taking a break by factors of 1.53 (increase of $53 \%$ ) and 1.14 (increase of 14\%) compared with those doing the FP in England (CI 1.36 to 1.72 and CI 1.01 to 1.30 , respectively). After controlling for the presence of multiple factors, the odds of taking a break from training for trainees with a parent educated to a degree level were multiplied by a factor 1.17 (increased by 17\%) compared with those who came from families where no parent was educated to a degree level (OR=1.17, CI 1.11 to 1.24).

\section{DISCUSSION}

\section{Main findings}

Our aim was to explore if there were differences between doctors who apply for specialty training in F2 and those who do not, instead taking time out of the formal training pathway. We looked specifically at individual characteristics, educational performance at medical school, foundation school and specialty preferences (indicated by a training place offer and accepting that offer). We found that, in terms of sociodemographics, those entering medicine after high school and doing a 5-year (standard) programme, males, of white ethnicity and whose parents 
Table 4 Relationships between sociodemographic variables and the odds of taking a break from the training pathway after Foundation Year 2

\begin{tabular}{|c|c|c|c|c|c|}
\hline & \multirow[b]{2}{*}{ Significance } & \multirow[b]{2}{*}{ OR } & \multicolumn{2}{|c|}{$95 \% \mathrm{Cl}$ for OR } \\
\hline & & & & Lower & Upper \\
\hline Gender & Female & $<0.001$ & 0.836 & 0.795 & 0.879 \\
\hline Age & Mature & $<0.001$ & 0.672 & 0.62 & 0.728 \\
\hline Ethnicity & Non-white & $<0.001$ & 0.769 & 0.727 & 0.814 \\
\hline POLAR & High participation areas & 0.14 & 1.097 & 0.97 & 1.241 \\
\hline $\begin{array}{l}\text { Parental } \\
\text { education }\end{array}$ & Parent degree level (yes) & $<0.001$ & 1.174 & 1.112 & 1.239 \\
\hline \multirow{4}{*}{$\begin{array}{l}\text { UK country of } \\
\text { origin }\end{array}$} & England & 0.001 & & & \\
\hline & Northern Ireland & $<0.001$ & 1.344 & 1.141 & 1.583 \\
\hline & Scotland & 0.173 & 0.927 & 0.831 & 1.034 \\
\hline & Wales & 0.251 & 1.071 & 0.953 & 1.204 \\
\hline \multirow{3}{*}{$\begin{array}{l}\text { Medical } \\
\text { programme }\end{array}$} & Standard 5-year degree & 0.163 & & & \\
\hline & $\begin{array}{l}\text { Graduate entry programme ( } 4 \\
\text { years) }\end{array}$ & 0.399 & 0.954 & 0.856 & 1.064 \\
\hline & 6 -year degree programme & $<0.001$ & 1.123 & 0.978 & 1.289 \\
\hline $\begin{array}{l}\text { High school } \\
\text { type }\end{array}$ & Independent/fee paying & 0.088 & 1.051 & 0.993 & 1.112 \\
\hline \multirow{4}{*}{$\begin{array}{l}\text { Foundation } \\
\text { School Region } \\
\text { (UK country) }\end{array}$} & England & $<0.001$ & & & \\
\hline & Northern Ireland & 0.071 & 1.202 & 0.984 & 1.467 \\
\hline & Scotland & $<0.001$ & 1.527 & 1.358 & 1.717 \\
\hline & Wales & 0.037 & 1.144 & 1.008 & 1.298 \\
\hline Constant & & $<0.001$ & 0.493 & & \\
\hline
\end{tabular}

The reference groups for the categorical variables were male gender, trainees who entered medical school as school leaver students (aged 20 years and below), those who identified their ethnicity as white, those who came from local areas of high participation in higher education (POLAR), trainees with no parent educated to degree level, trainees whose UK country is England, those who attended state-funded (high) school and those who attended a foundation school in England.

were educated to degree level were more likely to take time out of the training pathway than their counterparts.

Other than gender, all these factors are associated with socioeconomic status in the UK. ${ }^{40-42}$ While acknowledging the complex intersectionality between social class and ethnicity, ${ }^{42}$ broadly speaking this suggests that early career doctors from higher socioeconomic groups are less likely to choose to progress directly from the FP into specialty training. In relation to gender, women make up the majority of UK medical students nowadays although they are still in the minority in terms of the Consultant workforce. ${ }^{43}{ }^{44}$ Given this, it is of interest that significantly more women in the contemporary cohorts under study moved directly into specialty training immediately after F2 than did their male counterparts. Even drawing on other work using UKMED, it is difficult to get a clear picture as to why this is the case. We know that a higher proportion of women choose general practice, ${ }^{37}$ and this was a specialty that stood out as one of the few where most doctors did not intend to take a break from the training pathway. However, the same paper from Kumwenda et $a l^{37}$ illustrated that general practice is favoured by mature students, so equally this pattern may be related to age/ lifestage rather than gender. That this might be the case is supported by the fact those considering the diagnostic specialties (pathology, radiology) and psychiatry were also less likely to take a break from the training pathway: these specialties are also known to attract more mature doctors into training.

We were also intrigued by the fact that the figures for ACCS and 'undecided' were very similar in terms of nearly three-quarters of those who reported either of these choices planned to take a break from the training pathway. We suggest that this might be linked to the inherent nature of ACCS: as the original 'broad-based training' (BBT) in the UK, ${ }^{45}$ ACCS inherently provides trainees with extra time to decide on an onward career specialty compared with conventional CT/ST (Core Training/Specialty Training) pathways. In other words, ACCS (and the newer BBT pathways) provides early career doctors time to gain conviction in choice of career specialty from within a training programme. It seems some doctors want both time out of the formal training pathway and a broad-based core training programme, which is of interest. This requires further exploration. 


\section{Comparison with previous literature}

The 'gap year' literature is useful in considering the rationale for time out of training post-FP and the socioeconomic differences in doing so. A gap year is a break from an educational track, ${ }^{46}$ often taken between (high) school and university or between university and work. 'Taking a gap year' is a common pattern of behaviour in school pupils and students in some countries. It is considered a time to recuperate from previous educational experiences, resolve uncertainties about next steps in life ${ }^{47}$ (reflected in the findings that $66 \%$ of F2s who were undecided about their career preference did not go directly into core or specialty training) and make one's curriculum vitae (CV) more competitive. ${ }^{48} 49$ The medical education and training system in the UK is such that after the FP is the natural opportunity, or transition point, for a break from an otherwise linear and sometimes lengthy medical career trajectory. ${ }^{50}$ Indeed, our own and other research indicate that common reasons for pursuing an alternative career step post-FP are to recover from the rigours of the FP and to gain more experience in preferred specialties, to inform specialty choice. ${ }^{8}$ Recent qualitative work also suggests that many doctors view their time out post-FP experience as an opportunity to strengthen their CVs, to gain an edge over their peers in preparation for competitive specialty training (residency) selection processes especially in their preferred location. ${ }^{51}$ We may speculate these trainees see beyond a tightly organised system and make choices as to how they educate themselves. However, they have to afford to be able to take a risk in terms of not going directly into training and instead accepting relatively short-term contracts, which may be the reason why taking a break from the training pathway is more popular in those from higher socioeconomic groups, who are more likely to have family support (see below for further discussion).

Less positively, it also seems not proceeding directly into a training post after FP has the potential to perpetuate 'class' differences in medical education. The wider literature and our own findings indicate that delaying career choices is an unequally distributed privilege: gap years are still relatively uncommon among less advantaged groups. ${ }^{52-54}$ Indeed, the origin of the gap year is in The Grand Tour of educated young men from higher social classes in the 18th and 19th centuries. ${ }^{49}$ Doctors from less privileged backgrounds and/or those with more financial commitments, such as graduates and more mature students, ${ }^{55}$ may be less able to delay time to completion of training and first fully trained post. This may also be why we saw the greatest proportion of doctors not taking a year out of training going into GP, which has the shortest training of any specialty (indeed, other research has identified that graduates and those from lower socioeconomic groups are more likely to opt for a GP training pathway). ${ }^{37}$ This may be a disadvantage in terms of losing the option of a breathing space. On the contrary, older FP doctors may have stronger, more individualised CVs than their contemporaries who went directly from school to medical school, and they may also be more decided in terms of the specialty in which they wish to train. These possible differences in attitude towards benefits accrued, or wish for, a year out of the formal training pathway merit further investigation.

The areas where there was no significant difference between groups were also of interest. While there was a statistically significant difference between performance at medical school and taking time out of the current training pathway or not, the difference was so small that medians and quartiles for EPM in the two groups were identical. Other work with the UKMED database suggests that doctors who pursue careers in more competitive specialties have significantly higher UKFP selection scores, of which the EPM is a significant component, than those who pursued less competitive ones. ${ }^{51}$ It may be that doctors see taking an alternative career step post-F2 (ie, not proceeding directly into a training post) as advantageous to their later chances of getting a training post (residency) in a competitive specialty. Qualitative work is needed to explore this further.

The matter of doctors who are not offered training posts is one of interest if not a concern. The percentage $(5.3 \%)$ is relatively high given medical school and foundation are designed to create preparedness for advanced medical education. Is there a problem with their education in medical school or foundation that makes them unsuitable for appointment or is it a problem with selection processes? A few may be accounted for in that some specialties are oversubscribed but more are markedly undersubscribed. We suggest that, most likely, data would suggest the job may be right but the offer is at the wrong time and in the wrong geographical location. ${ }^{13} 52$

\section{Strengths and weaknesses of the study}

An important strength of this study is that it included foundation doctors across the UK and across multiple cohorts. UKMED incorporates a number of datasets, allowing for the first time, examination of the association between career-related behaviour (applying for a training post in F2 or not) and personal characteristics, such as socioeconomic background. UKMED holds more indicators of socioeconomic background than we included in our model. This was due to multicollinearity; that is, a strong relationship (or association) between variables. This is not surprising given they all measure socioeconomic status in some way, so we kept POLAR in the model as it is not self-declared information and is thus considered more accurate than some of the other measures. International medical students, who make up $7.5 \%$ of the UK medical student population, were not included in our analysis because their socioeconomic data is not held in UKMED. However, these students are eligible for the FP and specialty training pathways in the same way as 'home' students, and their continued contribution to the medical workforce and healthcare delivery is expected and indeed required. Unlike international medical graduates who come to the UK to work after graduating in 
another country, ${ }^{57-62}$ international students who graduate from UK medical students are a relatively understudied group. The relative patterns of this group compared with 'home' students merit further research.

We used the EPM score as an indicator of academic performance. As outlined earlier, this score comprises an individual's performance at medical school plus additional educational achievements. It is part of the package of measures used to make up the UKFP selection score and is not used as a stand-alone marker in practice. However, we used the EPM as the only marker of medical school performance available given the UK does not have a medical licensing examination at the current time. Future studies may wish to tease out the relationship between the different components of the EPM and personal characteristics. ${ }^{53}$ We did not examine the relationship between specialty choice and whether a doctor takes time out of the training pathway or not, in depth as the sheer number of specialties was problematic for analysis purposes. However, other authors have identified that doctors pursuing training positions in more competitive specialties have significantly higher academic scores than colleagues pursuing less competitive ones. ${ }^{37}$

We acknowledge that this study took place in one country, with, broadly speaking, one healthcare service and training environment. Given this, we would not assume that the findings of this study are generalisable across different systems or countries. However, where doctors are taking breaks from training at key points, it is important to understand the reasons. Comparative research is merited. In our previous research on selection into postgraduate (F2) training, we reported how some of the contextual markers included in the analysis overlap, particularly socioeconomic class, ethnicity and place of medical qualification. ${ }^{37}$ We believe that these have a similar effect on career behaviour given the links between place, poverty and ethnicity in the $\mathrm{UK}^{5455}$ but they are the only markers available to us. Finally, this is a quantitative study, so it tells us about aggregate patterns of behaviour, but it does not tell us the reasons for these patterns. To understand more about why doctors are taking time out of training post-FP requires in-depth exploratory work.

\section{IMPLICATIONS AND CONCLUSION}

Current discourse tends to adopt a stance that doctors who decide to take a break out of the current UK recognised training pathway after $\mathrm{F} 2$ are failing to conform. We propose a different discourse. It may be that they are doing what we seek to inspire in recent graduates, namely, to be self-directed life-long learners who are doing what they believe is best to establish themselves as fully fledged medical professionals. It may be that they are right in their approach and that in the long run they will be better doctors who have acquired broader and deeper education, which will enable sustained high-quality practice over their entire career. These suggestions can be explored in future research.
The medical education and training pathway in the UK is a linear model that is not designed to cope with large numbers of early career doctors taking time out of training before progression to specialty training. Yet, increasing numbers are doing so and this is unlikely to change in the future, given that newer generations seem to have a different outlook on how they wish to work and what is important to them. ${ }^{63}$ Further, the service has been adaptable and many are now employing these doctors in new roles such at development and teaching fellows. These new posts allow doctors dedicated time to develop their non-clinical role such as teaching or research, which many post-FP doctors now seem to be actively seeking. They see it as an opportunity both for a break in the training pathway and also to enhance their future applications.

Our study provides insight into which doctors are more or less likely to step out of the training pathway postF2. This new knowledge suggests that widening access and encouraging more socioeconomic diversity in our medical students may be helpful in terms of recruiting F2s into core/specialty training posts. Changing training systems so that changing between specialties is more straightforward may also be helpful-the GMC are already considering how doctors can move more readily from one training pathway to another without having to start again from the bottom. This paper provides some evidence that these actions may help reduce the trend for post-FP training breaks and keep doctors in training (ie, if they know it will be easier to 'ladder' across pathways and have their training recognised when doing so). Finally, it is time to acknowledge that the norm is not to progress from F2 to specialty training without a break and to consider system changes accordingly.

\section{Twitter Kim Walker @DrKim04793079}

Acknowledgements UK Medical Education Database ('UKMED') UKMEDP 046 extract generated on 20 July 2018 . We are grateful to UKMED for the use of these data. However, UKMED bears no responsibility for their analysis or interpretation. The data includes information derived from that collected by the Higher Education Statistics Agency Limited ('HESA') and provided to the GMC ('HESA Data'). HESA Student Record 2007/2008 and 2008/2009 Copyright Higher Education Statistics Agency Limited. The Higher Education Statistics Agency Limited makes no warranty as to the accuracy of the HESA Data, cannot accept responsibility for any inferences or conclusions derived by third parties from data or other information supplied by it.

Contributors JC led the funding bid, which was reviewed by KW, BK, GP and PJ. $\mathrm{KW}$ and PJ advised on the nature of the data. BK managed the data, carried out the data analysis under the supervision of GP and JC. GP advised on all the statistical analysis. JC wrote first draft of the introduction and discussion sections of this paper. BK prepared drafted methods and results sections, which JC edited. All authors reviewed and agreed on the final draft of the paper.

Funding Funding for this study was provided by the UK Foundation Programme Office (UKFPO), who commissioned the authors to carry out an independent analysis of the research question presented in this paper.

Competing interests KW was formerly the Special Advisor (Recruitment) for the UK's Foundation Programme (UKFPO).

Patient consent for publication Not required.

Ethics approval The Chair of the local ethics committee ruled that formal ethical approval was not required for this study given the fully anonymised data was held in safe haven. We did not involve patients or the public in our work. Approved for publication by the UKMED Advisory Board on 16 April 2019. 
Provenance and peer review Not commissioned; externally peer reviewed.

Data availability statement Data may be obtained from a third party and are not publicly available.

Open access This is an open access article distributed in accordance with the Creative Commons Attribution Non Commercial (CC BY-NC 4.0) license, which permits others to distribute, remix, adapt, build upon this work non-commercially, and license their derivative works on different terms, provided the original work is properly cited, appropriate credit is given, any changes made indicated, and the use is non-commercial. See: http://creativecommons.org/licenses/by-nc/4.0/.

\section{ORCID iD}

Ben Kumwenda http://orcid.org/0000-0003-1600-8229

\section{REFERENCES}

1 Addicott R, Maguire D, Honeyman M, et al. Workforce planning in the NHS. Available: https://www.kingsfund.org.uk/sites/default/files/field/ field_publication_file/Workforce-planning-NHS-Kings-Fund-Apr-15. pdf [Accessed 4 Dec 2018].

2 Gorman D. Developing health care workforces for uncertain futures. Academic Medicine 2015;90:400-3.

3 Baicker K, Chandra A. Medicare spending, the physician workforce, and beneficiaries' quality of care. Health Aff 2004;23:W4184-W4-197.

4 Arthur MB, Khapova SN, Wilderom CPM. Career success in a boundaryless career world. J Organ Behav 2005;26:177-202.

5 Rimmer A. Nearly half of trainees chose not to progress straight to specialty training in 2015, 2015. Available: https://www.bmj.com/ content/351/bmj.h6550 [Accessed 4 Dec 2018].

6 UK Foundation Programme Office. F2 careers destination report. Available: http://www.foundationprogramme.nhs.uk/sites/default/ files/2019-01/F2\%20Career\%20Destinations\%20Report_FINAL.pdf [Accessed Jan 2019].

7 General Medical Council (GMC). Training pathways: analysis of the transition from the foundation programme to the next stage of training. Available: https://www.gmc-uk.org/-/media/documents/ Training_pathways_1__FINAL2.pdf_72695703.pdf [Accessed Jan 2019].

8 Smith C, Low L. The gap between Foundation years and specialty training. BMJ 2012:e1109.

9 General Medical Council (GMC). Interactive reports to investigate factors that affect progression of doctors in training. Available: https://www.gmc-uk.org/-/media/documents/briefing-note---examsand-recruitment-outcome-reports_pdf-60060997.pdf [Accessed 4 Dec 2018].

10 Spooner S, Gibson J, Rigby D, et al. Stick or twist? career decisionmaking during contractual uncertainty for NHS junior doctors. BMJ Open 2017;7: 013756.

11 Scanlan GM, Cleland J, Walker K, et al. Does perceived organisational support influence career intentions? the qualitative stories shared by UK early career doctors. BMJ Open 2018;8:e022833.

12 Cleland J, Johnston P. Taking a break: doctors opt out of training after Foundation year 2. BMJ 2019;365.

13 General Medical Council (GMC). Progression reportsUpdated 2018 Available: https://www.gmc-uk.org/education/reports-and-reviews/ progression-reports [Accessed September, 2019].

$14 \mathrm{NHS}$ Improvement. Evidence from NHS improvement on clinical staff shortages. A workforce analysisUpdated 2016. Available: https:// assets.publishing.service.gov.uk/government/uploads/system/ uploads/attachment_data/file/500288/Clinical_workforce_report.pdf [Accessed September, 2019].

15 British Medical Association (BMA). Staffing crisis in NHS laid bare, as new BMA analysis shows that three quarters of medical Specialities face shortage of doctors. Available: https://www.bma.org.uk/news/ media-centre/press-releases/2017/september/staffing-crisis-in-nhslaid-bare [Accessed Sep 2019].

16 Lachish S, Goldacre MJ, Lambert T. Associations between perceived institutional support, job enjoyment, and intentions to work in the United Kingdom: national questionnaire survey of first year doctors. BMC Med Educ 2016;16:151.

17 Cleland J, Johnston P, Watson V, et al. What do UK doctors in training value in a post? a discrete choice experiment. Med Educ 2016:50:189-202.

18 Rich A, Viney R, Needleman S, et al. 'You can't be a person and a doctor': the work-life balance of doctors in training - a qualitative study. BMJ Open 2016;6:e013897.
19 Cleland JA, Johnston PW, Anthony M, et al. A survey of factors influencing career preference in new-entrant and exiting medical students from four UK medical schools. BMC Med Educ 2014; $14: 151$.

20 Taylor KS, Lambert TW, Goldacre MJ. Career progression and destinations, comparing men and women in the NHS: postal questionnaire surveys. BMJ 2009;338.

21 Gibis B, Heinz A, Jacob R, et al. The career expectations of medical students: findings of a nationwide survey in Germany. Dtsch Arzteb/ Int 2012:109:327-32.

22 Williams C, Cantillon P. A surgical career? the views of junior women doctors. Med Educ 2000;34:602-7.

23 Fréchette D, Hollenberg D, Shrichand A, et al. What's really behind Canada's unemployed specialists? Too many, too few doctors? Findings from the royal college's employment study. (the royal college of physicians and surgeons of Canada). Available: https:// www.longwoods.com/articles/images/rc_employment_report_2013. pdf [Accessed 4 Dec 2018]

24 Gorman DF, Brooks PM. On solutions to the shortage of doctors in Australia and New Zealand. Med J Aust 2009;190:152-6.

25 Patty A. Forecast oversupply of doctors to hit this year amid calls to halt imports. Sydney morning herald, 2017. Available: https://www. smh.com.au/business/workplace/forecast-oversupply-of-doctors-tohit-this-year-amid-calls-to-halt-imports-20170103-gtle76.html

26 Dowell J, Cleland J, Fitzpatrick S, et al. The UK medical education database (UKMED) what is it? why and how might you use it? BMC Med Educ 2018;18.

27 Kumwenda B, Cleland J, Greatrix R, et al. Are efforts to attract graduate applicants to UK medical schools effective in increasing the participation of under-represented socioeconomic groups? a national cohort study. BMJ Open 2018;8:e018946.

28 Rodriguez Santana I, Chalkley M. Getting the right balance? A mixed logit analysis of the relationship between UK training doctors' characteristics and their specialties using the 2013 national training survey. BMJ Open 2017;7:e015219.

29 Kumwenda B, Cleland JA, Walker K, et al. The relationship between school type and academic performance at medical school: a national, multi-cohort study. BMJ Open 2017;7:e016291.

30 Milburn A. University challenge: how higher education can advance social mobility. Available: https://www.gov.uk/government/uploads/ system/uploads/attachment_data/file/80188/Higher-Education.pdf [Accessed Mar 2018].

31 Mathers J, Sitch A, Marsh JL, et al. Widening access to medical education for under-represented socioeconomic groups: population based cross sectional analysis of UK data, 2002-6. BMJ 2011;342.

32 Griffin B, Hu W. The interaction of socio-economic status and gender in widening participation in medicine. Med Educ 2015;49:103-13.

33 Fielding S, Tiffin PA, Greatrix R, et al. Do changing medical admissions practices in the UK impact on who is admitted? an interrupted time series analysis. BMJ Open 2018;8:e023274.

34 Medical Workforce Standing Advisory Committee. Planning the medical workforce. Third report. Available: http://www.nhshistory.net/ mwfsac3.pdf [Accessed December 4, 2018].

35 Lievens F, Patterson F, Corstiens $\mathrm{J}$, et al. Widening access in selection using situational judgement tests: evidence from the UKCAT. Med Educ 2016;50:624-36.

36 Petty-Saphon K, Walker K, Patterson F, et al. Situational judgment tests reliably measure professional attributes important for clinical practice. Adv Med Educ Pract 2016;8:21-3.

37 Kumwenda B, Cleland JA, Prescott GJ, et al. Relationship between sociodemographic factors and selection into UK postgraduate medical training programmes: a national cohort study. BMJ Open 2018;8:e021329.

38 Smith DT, Tiffin PA. Evaluating the validity of the selection measures used for the UK's foundation medical training programme: a national cohort study. BMJ Open 2018;8:e021918.

39 General Medical Council (GMC). Royal College curricula. Available: https://www.gmc-uk.org/education/standards-guidance-andcurricula/curricula\#approved_curricula [Accessed 4 Dec 2018].

40 The Poverty Site. Low income and ethnicity. Available: http://www. poverty.org.uk/low-income-and-ethnicity/ [Accessed 4 Dec 2018].

41 Social Mobility Commission. Ethnicity, gender and social mobility, 2016. Available: https://assets.publishing.service.gov.uk/ government/uploads/system/uploads/attachment_data/file/ 579988/Ethnicity_gender_and_social_mobility.pdf [Accessed 4 Dec 2018].

42 Strand S. Ethnicity, deprivation and educational achievement at age 16 in England: trends over time, 2015. Available: https://www.gov.uk/ government/uploads/system/uploads/attachment_data/file/439867/ RR439B-Ethnic minorities and attainment the effects of poverty annex.pdf.pdf [Accessed 4 Dec 2018]. 
43 Jefferson L, Bloor K, Maynard A. Women in medicine: historical perspectives and recent trends. Br Med Bull 2015;114:5-15.

44 Khan M, Dharma B. Medicine - a woman's world? BMJ 2012;344:d8234

45 General Medical Council (GMC). Broad based training. Available: https://www.gmc-uk.org/education/standards-guidance-andcurricula/curricula/broad-based-training [Accessed Sep 2019].

46 Heinz WR. Structure and agency in transition research. Journal of Education and Work 2009;22:391-404.

47 Vogt KC. The timing of a time out: the gap year in life course context. Journal of Education and Work 2018;31:47-58.

48 Holdsworth $\mathrm{C}$. The cult of experience: standing out from the crowd in an era of austerity. Area 2017;49:296-302.

49 Heath S. Widening the gap: pre-university gap years and the 'economy of experience'. Br J Sociol Educ 2007;28:89-103.

50 Erikson E. Identity, youth and crisis. New York: WW Norton Company, 1969.

51 Rizan C, Montgomery J, Ramage C, et al. Why are UK junior doctors taking time out of training and what are their experiences? A qualitative study. J R Soc Med 2019;112:192-9.

52 Jones A. Review of gap year provision, Research report. Department for Education and Skills, 2004.

53 Cremin C. Living and really living: the gap year and the commodification of the contingent. Ephemera 2007;7:526-42.

54 Stehlik T. Mind the gap: school leaver aspirations and delayed pathways to further and higher education. Journal of Education and Work 2010;23:363-76.

55 Grayson MS, Newton DA, Thompson LF. Payback time: the associations of debt and income with medical student career choice. Med Educ 2012;46:983-91.
56 Pyne Y, Ben-Shlomo Y. Older doctors and progression through specialty training in the UK: a cohort analysis of general medical Council data. BMJ Open 2015;5:e005658.

57 British Medical Association (BMA). Migration Advisory Committee call for evidence: the impact of international students in the UK. Available: https://www.bma.org.uk/-/media/files/pdfs/collective\% 20voice/influence/uk\%20governments/consultation-response-macstudents-commission-august-2017.pdf?la=en [Accessed Sep 2019].

58 Pattinson J, Blow C, Sinha B, et al. Exploring reasons for differences in performance between UK and international medical graduates in the membership of the Royal College of general practitioners applied knowledge test: a cognitive interview study. BMJ Open 2019;9:e030341.

59 Patterson F, Tiffin PA, Lopes S, et al. Unpacking the dark variance of differential attainment on examinations in overseas graduates. Med Educ 2018;52:736-46.

60 Wakeford R. Country of qualification is linked to doctors' general medical Council performance assessment rate, but is it linked to their clinical competence? BMC Med 2017;15:149.

61 Mehdizadeh L, Potts HWW, Sturrock A, et al. Prevalence of GMC performance assessments in the United Kingdom: a retrospective cohort analysis by country of medical qualification. BMC Med Educ 2017;17:67

62 Tiffin PA, Paton LW, Mwandigha LM, et al. Predicting fitness to practise events in international medical graduates who registered as UK doctors via the professional and linguistic assessments board (PLAB) system: a national cohort study. BMC Med 2017;15:66.

63 Twenge JM, Campbell SM. Generational differences in psychological traits and their impact on the workplace. J Managerial Psych 2008;23:862-77. 